\title{
An autopsy review of sudden unexpected natural deaths in a suburban Nigerian population
}

\author{
Olumuyiwa Eyitayo Pelemo ${ }^{1}$, Donatus Sabageh ${ }^{2 *}$, Akinwumi Oluwole Komolafe ${ }^{1}$, Adedayo Olukemi Sabageh ${ }^{3}$ \\ and William Olufemi Odesanmi ${ }^{1}$
}

\begin{abstract}
Background: The pattern of diseases causing sudden unexpected natural deaths is a function of the prevalent disease pattern in the general population. This pattern appears to be changing in Nigeria in response to changing demographics and lifestyle.

Methods: This was a descriptive retrospective autopsy-based review of cases of sudden unexpected natural deaths seen at the Obafemi Awolowo University Teaching Hospitals Complex in lle-lfe, Nigeria (OAUTHC) over a 10-year period. Analysis was done for differences in proportion using Chi square ( $p$ is significant at $<0.05$ ) by SPSS version 15.

Results: Sudden unexpected natural deaths accounted for $13.4 \%$ of all medico-legal autopsies. The male to female ratio was 2.1:1, and the mean age was 43.1 years \pm 19.5 SD. Cardiovascular (28.3\%), respiratory (18.2\%), and central nervous system (12.6\%) disorders were the major groups of causes. About $64.4 \%$ of cardiovascular deaths were due to hypertensive heart disease. Bacterial pneumonia, intracerebral haemorrhage, and breast carcinoma accounted for $34.4 \%, 60.0 \%$, and $52.6 \%$ of respiratory, central nervous system, and cancer-related deaths respectively. Infectious causes predominated in all age groups below 40 years and above 70 years while hypertensive disorders predominated between 40 and 70 years. Only 16.9\% of cases occurred while the patient was admitted to the hospital.

Conclusion: Cardiovascular, respiratory, central nervous system, and cancer-related causes were the major causes of sudden unexpected natural deaths in our series. Hypertension-related disorders constituted a large proportion of cases especially in people over 40 years, whereas infectious diseases were more common below this age. The majority of deaths occurred outside the hospital setting. It is imperative that appropriate public health strategies be developed to address these issues.
\end{abstract}

Keywords: Autopsy review, Sudden unexpected natural deaths, Nigerian population

\section{Background}

Although there are controversies over the definition of the time frame for sudden unexpected death, the World Health Organisation (WHO) defines it as "death within 24 hours from the onset of symptoms" [1]. Mason, however, defines it as "unexpected death following so rapidly from the onset of symptoms that the cause of death could not be certified with confidence by a medical practitioner familiar with the patient" [2]. Specification of the time frame for sudden death is often unnecessary, since this cannot be determined in up to $40 \%$ of cases,

\footnotetext{
* Correspondence: dsabageh@yahoo.com

${ }^{2}$ Department of Morbid Anatomy and Histopathology, Ladoke Akintola

University of Technology, Ogbomoso, Oyo State, Nigeria

Full list of author information is available at the end of the article
}

especially when death occurs during sleep [3]. From a forensic point of view, however, sudden unexpected death is mainly defined as a rapid, unexpected, and natural death. This includes a healthy, non-fatally ill, or bedridden person who dies suddenly and unexpectedly (presumably from natural causes) as well as patients who die within 24 hours of admission into the hospital. Interestingly, sudden death is not necessarily unexpected, and an unexpected death is not necessarily sudden. Nevertheless, these two attributes often co-exist [4].

The incidence of sudden unexpected natural deaths is known to vary in different parts of the world and may reflect the respective levels of development of the individual country's death registration and medico-legal autopsy systems $[3,5-10]$. 
Although cardiac causes are the leading causes of sudden unexpected natural death worldwide, the exact nature of the implicated cardiac diseases as well as the exact incidence of the other causes of sudden death is not well established in many countries because many cases of sudden death are not autopsied [3]. The pattern of diseases causing sudden unexpected natural deaths is also known to be a function of the prevalent diseases in the general population [3]. For the Nigerian population this pattern appears to be changing, especially in response to changing demographic patterns and lifestyle [11,12].

It seems worthwhile, therefore, to review the pattern of the various causes of sudden unexpected natural deaths in a typical Nigerian population and to compare these findings with previous work done in the same area and in other parts of the world.

\section{Methods}

This is an observational, retrospective, descriptive study that included all cases of sudden unexpected natural deaths from January 2001 to December 2010 for which a postmortem was performed in the Department of Morbid Anatomy and Forensic Medicine, Obafemi Awolowo University Teaching Hospitals Complex (OAUTHC), in Ile-Ife, Osun State, Nigeria.

The department offers coroner services to the IfeIjesha zone of Nigeria, which has a population of over $1,500,000$ people. This is a semi-urban, diverse population that consists of individuals from all walks of life. According to the 2006 census, 43.8\%, 19.3\%, 30.1\%, and $3.8 \%$ of the Nigerian population are respectively between the ages of $0-14$ years, $15-24$ years, 25-54 years, and 55-60 years, while only $3.0 \%$ are older than 65 years [13]. There is an overall equal sex distribution although there is a very slight female preponderance after age 25 .

Legislation requires that a complete forensic autopsy (including histopathological examination and toxicological analysis) be performed on all cases of sudden unexpected natural (non-violent) deaths both in hospitalized and non-hospitalized persons.

The postmortem records of the department were examined for case selection. All cases of death referred to our department as suspected sudden and unexpected natural death were included in the study, since the strict time limit required for the presence of symptoms before death could not be determined in the majority of cases. Cases with incomplete clinical and/or autopsy records where a definitive anatomic diagnosis could not be arrived at were excluded from the study. For cases so identified, the hospital records, full postmortem reports, contemporary notes, and other collateral information were retrieved and studied. It is usual practice for the attending pathologist to ask for other relevant information concerning the deceased person's state of health while alive as well as the circumstances surrounding his/her death from the relatives of the deceased.

For the purpose of this study hypertensive heart disease was defined as any hypertrophied heart whether or not in failure associated with anatomic evidence of suggestive of systemic hypertension after excluding significant coronary artery disease and valvular heart disease.

Relevant data was collected and analysed for differences in proportion using Chi square ( $\mathrm{p}$ is significant at $<0.05$ ) by SPSS version 15 .

All data were treated confidentially. Ethical approval was obtained from the local ethics committee of the Obafemi Awolowo University Teaching Hospitals Complex, Ile-Ife, Osun State, Nigeria.

\section{Results}

Within the period under review, a total of 1,238 medicolegal autopsies were performed in the Department of Morbid Anatomy and Histopathology of the Obafemi Awolowo University Teaching Hospitals Complex. Of these, there were 166 cases (13.4\%) of sudden unexpected natural deaths. However, only 159 cases of sudden unexpected natural deaths had complete clinical and/or autopsy information relevant to this study and thus formed the study population. Of these 159 cases, there were 108 males (67.9\%) and 51 females (32.1\%) giving a male to female ratio of 2.1:1. The age range was from about 3 years to 83 years, and the mean age was 43.1 years \pm 19.5 SD. About 86 cases $(54.1 \%)$ were older than 40 years old at the time of death while 73 cases (45.9\%) were younger than 40 years (Figure 1).

Figure 1 shows the age and sex distribution of all cases. The vast majority of cases (82.4\%) were clustered between ages 21 and 70 years with the highest number of cases seen in the $21-30$ year age group (33 cases (20.8\%)). There were only 16 cases $(10.1 \%)$ younger than 20 years old and

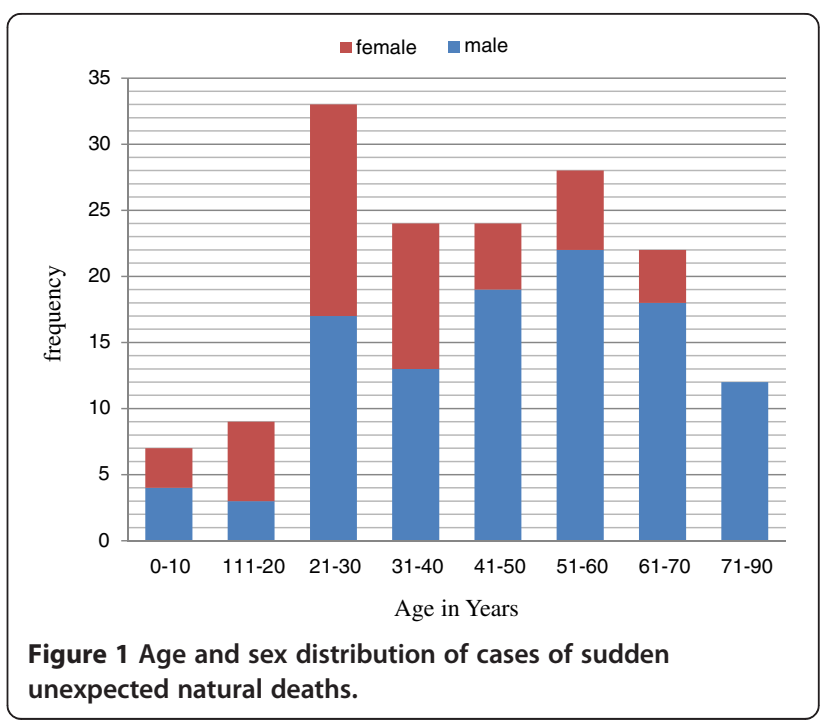


12 cases $(7.5 \%)$ older than 70 years old. In all age groups males predominated over females except in the adolescent age group where there was a very slight female preponderance. There were no females over the age of 70 years.

Table 1 shows the breakdown of the various causes of sudden unexpected natural deaths. The leading causes of death were due to cardiovascular (28.3\%), respiratory (18.2\%), and central nervous system (12.6\%) disorders. Together, these accounted for more than half the total number of cases (59.1\%). Surprisingly, cancer-related deaths also accounted for a significant proportion of cases (11.9\%). Overall, the leading specific causes (55.3\%) of sudden unexpected natural death were hypertensive heart disease (18.2\%), intracerebral hemorrhage (7.5\%), chronic glomerulonephritis (6.3\%), breast carcinoma (6.3\%), bacterial pneumonia (6.3\%), aspiration pneumonia (5.7\%), and diabetic ketoacidosis (5.0\%).

About $64.4 \%$ of cardiovascular deaths resulted from complications associated with hypertensive heart disease while coronary artery disease accounted for only $15.6 \%$ of cases. On the other hand, bacterial pneumonia (34.4\%) and aspiration pneumonitis (31.0\%) accounted for the majority of deaths from respiratory causes, although pulmonary tuberculosis (17.2\%) and complications of bronchial asthma (17.2\%) contributed significantly. Intracerebral haemorrhage (60.0\%) and pyogenic meningitis (30.0\%)

Table 1 Principal causes of death by system

\begin{tabular}{|c|c|c|c|c|}
\hline \multirow[t]{2}{*}{ System } & \multirow[t]{2}{*}{ Causes of death (\% per system) } & \multicolumn{2}{|l|}{ No. of cases } & \multirow{2}{*}{$\begin{array}{l}(\% \text { of Total }) \\
N=159\end{array}$} \\
\hline & & Male (108) & Female (51) & \\
\hline \multirow[t]{7}{*}{ Cardiovascular $(\mathrm{N}=45)$} & Hypertensive heart disease (64.4) & 25 & 4 & $29(18.2)$ \\
\hline & Coronary artery disease (15.6) & 5 & 2 & $7(4.4)$ \\
\hline & Dilated cardiomyopathy (6.7) & 3 & 0 & $3(1.9)$ \\
\hline & Hypertrophic cardiomyopathy (4.4) & 2 & 0 & $2(1.3)$ \\
\hline & Rheumatic heart disease (4.4) & 1 & 1 & $2(1.3)$ \\
\hline & Ruptured aortic aneurysm (2.2) & 1 & 0 & $1(0.6)$ \\
\hline & Constrictive pericarditis (2.2) & 1 & 0 & $1(0.6)$ \\
\hline \multirow[t]{4}{*}{ Respiratory $(\mathrm{N}=29)$} & Bacterial pneumonia (34.4) & 9 & 1 & $10(6.3)$ \\
\hline & Aspiration pneumonitis (31.0) & 7 & 2 & $9(5.7)$ \\
\hline & Tuberculosis (17.2) & 3 & 2 & $5(3.1)$ \\
\hline & Asthma (17.2) & 5 & 0 & $5(3.1)$ \\
\hline \multirow[t]{4}{*}{ Central nervous $(\mathrm{N}=20$ ) } & Intracerebral hemorrhage (60.0) & 12 & 0 & $12(7.5)$ \\
\hline & Pyogenic meningitis (30.0) & 4 & 2 & $6(3.8)$ \\
\hline & Epilepsy (5.0) & 1 & 0 & $1(0.6)$ \\
\hline & Carvenous sinus thrombosis (5.0) & 0 & 1 & $1(0.6)$ \\
\hline \multirow[t]{5}{*}{ Cancer-related death $(\mathrm{N}=19)$} & Breast carcinoma (52.6) & 0 & 10 & $10(6.3)$ \\
\hline & Colorectal carcinoma (21.1) & 4 & 0 & $4(2.5)$ \\
\hline & Pancreatic carcinoma (5.3) & 1 & 0 & $1(0.6)$ \\
\hline & Non-Hodgkin's lymphoma (10.5) & 1 & 1 & $2(1.3)$ \\
\hline & Acute myeloid leukaemia (10.5) & 0 & 2 & $2(1.3)$ \\
\hline \multirow[t]{3}{*}{ Obstetric ( $N=12)$} & Spontaneous abortion (58.3) & 0 & 7 & $7(4.4)$ \\
\hline & Ruptured tubal gestation (25.0) & 0 & 3 & $3(1.9)$ \\
\hline & Anemia in pregnancy (16.7) & 0 & 2 & $2(1.3)$ \\
\hline Renal $(N=10)$ & Chronic glomerulonephritis (100.0) & 8 & 2 & $10(6.3)$ \\
\hline Lymphoreticular ( $N=5)$ & Sickle cell diseases (55.6) & 2 & 3 & $5(3.1)$ \\
\hline \multirow[t]{3}{*}{ Gastrointestinal $(N=6)$} & Gastroenteritis (50.0) & 3 & 0 & $3(1.9)$ \\
\hline & Perforated typhoid enteritis (33.3) & 0 & 2 & $2(1.3)$ \\
\hline & Perforated duodenal ulcer (16.7) & 1 & 0 & $1(0.6)$ \\
\hline Endocrine $(\mathrm{N}=8)$ & Diabetic ketoacidosis (100.0) & 6 & 2 & $8(5.0)$ \\
\hline \multirow[t]{2}{*}{ Miscellaneous ( $(=5)$} & Tetanus (23.1) & 1 & 2 & $3(1.9)$ \\
\hline & Spontaneous splenic rupture (15.4) & 2 & 0 & $2(1.3)$ \\
\hline
\end{tabular}


accounted for the majority of disorders in the central nervous system. All cases of intracerebral hemorrhage were associated with anatomic evidence of background systemic hypertension. Cancer-related deaths were more commonly seen in women, with breast carcinoma (52.6\%) accounting for the majority of such cases. Cancer-related deaths seen in men included colorectal (21.1\%) and pancreatic (5.3\%) carcinoma as well as non-Hodgkin lymphoma (5.25\%). Sudden death from obstetric causes accounted for only 12 cases $(7.5 \%)$ with spontaneous abortion (58.3\%) and ruptured tubal ectopic pregnancy (25.0\%) accounting for the majority. Only two cases (16.7\%) were due to severe anaemia in pregnancy. About 10 cases $(6.3 \%)$ were due to chronic glomerulonephritis with a male to female ratio of 4:1. Complications from sickle cell disease accounted for the majority $(55.6 \%)$ of deaths from disorders of the lymphoreticular system. Non-Hodgkin's lymphoma and acute myeloid leukemia accounted for the remainder, with two cases $(22.2 \%)$ each. Severe gastroenteritis accounted for half of gastrointestinal causes with intestinal perforation due to typhoid enteritis (33.3\%) and duodenal ulcer $(16.7 \%)$ accounting for the remainder. The five cases classified as miscellaneous included three cases of tetanus and two cases of spontaneous rupture of the spleen.

Table 2 shows the most prevalent causes of death per age group. While infectious diseases predominated below the age of 40 years and above the age of 70 years, hypertensive disorders were the leading causes in all age groups between 40 and 70 years.

Only $16.9 \%$ of cases occurred while the patient was admitted to the hospital; the vast majority $(83.1 \%)$ of cases occurred outside the hospital setting (Table 3).

\section{Discussion}

The frequency and pattern of sudden unexpected natural deaths are known to reflect the disease pattern prevalent in any particular geographic location, and thus vary in different parts of the world. Nevertheless, it is well established in many studies that the cardiovascular, respiratory, and central nervous systems constitute the most common organ systems contributing to sudden unexpected natural deaths $[1,6,14,15]$. This fact is well corroborated by this study, which showed that cardiovascular, respiratory, central nervous system, and cancerrelated disorders respectively accounted for $28.3 \%, 18.8 \%$, $12.6 \%$, and $11.9 \%$ of cases. Interestingly, however, in contrast to many reports from developed countries where coronary artery disease was the single most common cause of sudden unexpected death, this study showed that hypertensive heart disease was the single most prevalent cause of sudden unexpected natural death. It accounted for $18.2 \%$ of all cases and $64.4 \%$ of cardiovascular causes. This fact becomes more significant as this study also shows that intracerebral hemorrhage was the second most prevalent
Table 2 Most prevalent causes of death per age group

\begin{tabular}{|c|c|c|}
\hline $\begin{array}{l}\text { Age group in years } \\
\text { (no. of cases) }\end{array}$ & $\begin{array}{l}\text { Most prevalent causes } \\
\text { of death }\end{array}$ & $\begin{array}{l}\text { No of cases } \\
\text { (\% per age group) }\end{array}$ \\
\hline \multirow[t]{3}{*}{$0-10(n=7)$} & Gastroenteritis & $3(42.8)$ \\
\hline & Bacterial pneumonia & $2(28.5)$ \\
\hline & Pyogenic meningitis & $2(28.5)$ \\
\hline \multirow[t]{3}{*}{$11-20(n=9)$} & Pyogenic meningitis & $4(44.4)$ \\
\hline & Aspiration pneumonitis & $2(22.2)$ \\
\hline & Acute myeloid leukemia & $2(22.2)$ \\
\hline \multirow[t]{4}{*}{$21-30(n=33)$} & Aspiration pneumonitis & $7(21.2)$ \\
\hline & Spontaneous abortion & $5(15.1)$ \\
\hline & Sickle cell disease & $5(15.1)$ \\
\hline & Asthma & $5(15.1)$ \\
\hline \multirow[t]{4}{*}{$31-40(n=24)$} & Bacterial pneumonia & $6(25.0)$ \\
\hline & Hypertensive heart disease & $5(20.8)$ \\
\hline & Ruptured tubal gestation & $3(12.5)$ \\
\hline & Dilated cardiomyopathy & $3(12.5)$ \\
\hline \multirow[t]{4}{*}{$41-50(n=24)$} & Hypertensive heart disease & $9(37.5)$ \\
\hline & Colorectal carcinoma & $4(16.7)$ \\
\hline & Coronary artery disease & $4(16.7)$ \\
\hline & Dilated cardiomyopathy & $3(12.5)$ \\
\hline \multirow[t]{3}{*}{$51-60(n=28)$} & Hypertensive heart disease & $9(32.1)$ \\
\hline & Breast carcinoma & $5(20.8)$ \\
\hline & Tuberculosis & $3(10.7)$ \\
\hline \multirow[t]{3}{*}{$61-70(n=22)$} & Intracerebral hemorrhage & $8(36.4)$ \\
\hline & Hypertensive heart disease & $3(13.6)$ \\
\hline & Tetanus & $3(13.6)$ \\
\hline \multirow[t]{4}{*}{$71-90(n=12)$} & Pneumonia bacteria & $5(41.7)$ \\
\hline & Hypertensive heart disease & $3(25.0)$ \\
\hline & Intracerebral haemorrhage & $2(16.7)$ \\
\hline & Tuberculosis & $2(16.7)$ \\
\hline
\end{tabular}

Table 3 Place of death

\begin{tabular}{ll}
\hline PLACE OF DEATH & No. (\%) \\
\hline Home & $40(25.2)$ \\
Public place & $33(20.8)$ \\
Motor vehicle & $30(18.9)$ \\
Hospital & $27(16.9)$ \\
Workplace & $21(13.2)$ \\
Jail & $2(1.3)$ \\
Sports ground & $2(1.3)$ \\
Other & $4(2.6)$ \\
Total & $159(100.0)$ \\
\hline
\end{tabular}


cause of death, since virtually all cases were associated with anatomic evidence of background essential hypertension. Moreover, this study showed that hypertensionrelated disorders were the leading causes of death in all age groups between 40 and 70 years. This highlights the critical role played by uncontrolled and/or undiagnosed essential hypertension as a cause of sudden unexpected natural death in Nigeria. Indeed, essential hypertension (and its complications) is the most common noncommunicable disease in Nigeria. It is also the most common cardiovascular disease among Africans [16]. However, it is well documented that there is a low level of awareness about hypertension in the Nigerian population $[12,17]$. Thus, the majority of people are unaware that they have the disease and remain untreated until either complications set in or they die suddenly [5]. In fact, a previous study carried out in the same center as ours showed that hypertensive heart disease was the cause of sudden unexpected natural death in $82 \%$ of cases, of which only $18 \%$ were previously diagnosed [12]. Although coronary artery disease is still relatively uncommon among Nigerians and does not contribute significantly to morbidity and mortality, this study seems to suggest that its incidence may be increasing within the Nigerian population, contrary to previously held views $[12,18,19]$. This may simply be a reflection of the changing lifestyles of the Nigerian population in response to strong Western cultural influences [20]. On the other hand, this may just be due to an arbitrary increase in the number of such cases referred for autopsy, perhaps as a result of an increased awareness within the population of the role of the autopsy in such cases.

This study also showed that bacterial pneumonia and aspiration pneumonitis accounted for about $65.4 \%$ of respiratory causes of sudden death. While this is similar to findings from other developing countries, it sharply contrasts with what is seen in developed countries where thromboembolic disorders account for the majority of cases $[1,4]$. In a study conducted in Cape Town, South Africa, although pneumonia was the most prevalent cause of death between the people aged 18 and 29 years, coronary artery disease was more prevalent between the ages of 30 and 39 years [1]. In addition, a study conducted in the north central part of Nigeria showed that although heart failure was the most common cause of death overall, pulmonary thromboembolism was the major cause of death attributed to the respiratory system [11]. This contrasts with our study, which showed that aspiration pneumonitis and bacterial pneumonia were the major causes of death within the young adult population especially between the ages of 21 years and 40 years. Bacterial pneumonia was also the major cause of death in individuals older than 70 years of age. The contributions by bacterial pneumonia and aspiration pneumonitis seem to underscore the important role played by various infectious disorders in sudden unexpected deaths. Together, infectious disorders constitute about $23.9 \%$ of all causes of sudden death. This becomes significant because infectious disorders are not only preventable but treatable causes of death, especially when antibiotics are appropriately and timely instituted.

The fact that about $83.1 \%$ of all cases occurred outside the hospital setting suggests that the majority of these victims were either not aware of their prevailing medical conditions or refused to seek appropriate medical intervention. It, therefore, becomes imperative to evolve strategies that will help educate the entire population about the significance of the signs and symptoms of various medical conditions and need to seek medical advice early. Efforts should also be geared toward making health care facilities readily accessible. This observation is further buttressed by results from this study, which showed that about $11.9 \%$ and $6.3 \%$ all cases of sudden death resulted from malignant diseases and chronic glomerulonephritis, diseases which are not acute in nature as would have been suggested by the mode of death. In fact, a little over half of such cases were due to breast carcinoma which affects a readily accessible organ in the body.

This study showed a male preponderance, with an overall male to female ratio of 2.1:1. With regards to cardiovascular causes, however, the male to female ratio was about 5.4:1. These findings are similar to what has been reported in various studies, both from Nigeria and other parts of the world $[11,20]$. This gender disparity becomes more prominent over the age of 30 years and may be partly related to the cardioprotective effect of estrogen in women before menopause as opposed to the testosterone-induced increase in cardiovascular risk [20]. The gender disparity observed in other causes of sudden death in this study cannot be readily explained.

The mean age from this study was $43.1 \pm 19.5$ years. This is about a decade younger than what was observed in various studies conducted many years earlier in the same region of the country $[8,12,20]$. This seems to suggest that the effects of environmental factors on the health of the population due to its relentless efforts at urbanization and the shift toward a Western lifestyle may be occurring at a much earlier age. Interestingly, many of these factors, which are known to increase cardiovascular risk, a major cause of sudden unexpected death, are readily amenable to preventive public health care measures and lifestyle changes. It is also instructive to note that the majority of deaths (68.6\%) according to this study occurred within the most productive age group of the population (21 to 60 years), which constitute about $42.6 \%$ of the Nigerian population according to the 2006 census [13].

According to this study, sudden unexpected natural death accounted for only $13.4 \%$ of all medico-legal 
autopsies, a figure similar to those from other developing countries, but much lower than seen in developed countries, where rates over $75 \%$ have been recorded [9]. This is because in Nigeria, sudden unexpected deaths caused by accidents, homicides, and suicide are major indications for medico-legal autopsy unlike sudden unexpected natural deaths [21]. On the other hand, the majority of sudden unexpected natural deaths occur outside of the hospital setting (as observed in this study), and these may not have been reported to the appropriate authority nor brought to the hospital for proper certification, thereby precluding any form of enquiry. It, therefore, becomes important that appropriate mass education programs and laws are put in place to ensure that all cases of sudden unexpected natural deaths are reported to the appropriate authorities so that detailed enquiries may be conducted on such cases, as this will impact greatly on our health care delivery system.

\section{Study limitations}

The authors hereby acknowledge that the conclusions drawn from this study may be wrong and not necessarily applicable to the general population because the study was based on autopsies performed on cases of sudden unexpected natural deaths in a tertiary health institution to the exclusion of those for which autopsy was not performed.

\section{Conclusion}

Cardiovascular, respiratory, central nervous system, and cancer-related disorders were the predominant causes of sudden unexpected natural deaths in our series, while hypertensive heart disease and intracerebral haemorrhage were the most prevalent individual causes. Hypertensionrelated disorders were mainly seen in people between 40 and 70 years of age, while infectious disorders were more commonly seen below 40 years and above 70 years. The majority of deaths occurred outside the hospital setting.

These findings seem to suggest that environmental factors play important roles in sudden unexpected natural deaths in Nigeria. Appropriate public health measures need to be put in place to address these issues.

\section{Competing interests}

The authors declare that they have no competing interests.

\section{Authors' contributions}

OEP was involved in the conceptualization and study design. He was also involved in the collection, analysis, and interpretation of the data and literature review. He made significant contributions during the drafting of the manuscript. DS was involved in the conceptualization and study design. He was also involved in the interpretation of the data. He also wrote the first and final drafts of the manuscript. AOK was involved in the conceptualization and study design. He supervised the collection of data and was involved in the critical revision of the manuscript for intellectual content. AOS was involved in the interpretation of data and critical review of the manuscript for intellectual content, especially with regards to public health. WOO was involved in the conceptualization and study design. He was also involved in the interpretation of the data and in the critical revision of the manuscript for intellectual content.
The manuscript has been read and approved by all the authors each of which has met the approved requirements for authorship. Each author also believes that this manuscript represents honest work. This information has not been provided in another form. All authors read and approved the final manuscript.

\section{Author details}

${ }^{1}$ Department of Morbid Anatomy and Forensic Medicine, Obafemi Awolowo University Teaching Hospitals Complex, lle-Ife, Osun State, Nigeria.

${ }^{2}$ Department of Morbid Anatomy and Histopathology, Ladoke Akintola University of Technology, Ogbomoso, Oyo State, Nigeria. ${ }^{3}$ Department of Community Medicine, Ladoke Akintola University of Technology Teaching Hospital, Osogbo, Osun State, Nigeria.

Received: 11 February 2014 Accepted: 24 September 2014

Published online: 04 October 2014

\section{References}

1. Tiemensma M, Burger EH: Sudden and unexpected deaths in an adult population, Cape Town, South Africa, 2001-2005. S Afr Med J 2012, 102(Suppl 2):90-94.

2. Mason JK: Forensic Medicine for Lamyers. 3rd edition. London: Butterworths; 1995.

3. de la Gradmaison GL: Is there progress in the autopsy diagnosis of sudden unexpected death in adults? Forensic Sci Int 2006, 156:138-144.

4. Mohamed EY, Abdelbadie A, Abdalla SM, Alsideg A, Khamis AH: Sudden natural death in Khartoum mortuary. Sud J Med Sci 2008, 3(Suppl 4):317-321.

5. Aligbe JU, Akhiwu WO, Nwosu SO: Prospective study of coroner's autopsies in Benin City, Nigeria. Med Sci Law 2002, 42(Suppl 4):18-24.

6. Amakiri CNT, Akang EEU, Aghadiuno PU, Odesanmi WO: A prospective study of coroner's autopsies in University College Hospital, Ibadan, Nigeria. Med Sci Law 1997, 37(Suppl 1):69-75.

7. Elmes RGT: Forensic Medicine in Uganda: A five year survey. East Afr Med J 1957, 34(Suppl 2):41-45.

8. Odesanmi WO: Forensic Medicine in Nigeria: The Ife experience. Med Sci Law 1982, 22(Suppl 4):269-274.

9. Broderick N: Death certification and the coroners. In Grawohl's Legal Medicine. Edited by Francis E. Camps Bristol: John Wright and Sons Ltd; 1971:221.

10. Escoffery CT: Causes of sudden natural death in Jamaica: A medico-legal autopsy study from the University Hospital of the West Indies. Forensic Sci Int 2002, 129(Suppl 2):116-121.

11. Mandong BM, Manasseh AN, Ugwu BT: Medicolegal autopsies in North Central Nigeria. East Afr Med J 2006, 83(Suppl 11):626-630.

12. Rotimi O, Ajayi A, Odesanmi WO: Sudden unexpected death from cardiac causes in Nigerians: A review of 50 autopsied cases. Int J Cardiology 1998, 63:111-115.

13. Central Intelligence Agency: The World Factbook; [https://www.cia.gov/ library/publications/the-world-factbook/geos/ni.html]

14. Sarkioja T, Hirvoren J: Causes of sudden unexpected deaths in young and middle aged persons. Forensic Sci Int 1984, 24:247.

15. Anderson RE, Hill RB, Broudy DW, Key CR, Pathak D: A population based autopsy of sudden unexpected deaths from natural causes among persons aged 5 to 39 years old during a 12 year perios. Human Pathol 1994, 25:1332-1340.

16. Akinkugbe OO: World epidemiology of hypertension in blacks. J Clin Hypertens 1987, 3(Suppl 1):1-8.

17. Oladapo OO, Salako L, Sodiq O, Soyinka K, Adedapo K, Falase AO: A prevalence of cardiometabolic risk factors among a rural Yoruba South-Western Nigeria population: A population-based survey. Cardiovasc J Afr 2010, 21:26-31.

18. Nwaneli CU: Changing trend in coronary heart disease in Nigeria. Afrimedic Journal 2010, 1(Suppl 1):1-4.

19. Rotimi O, Fatusi AO, Odesanmi WO: Sudden cardiac death in Nigerians The lle-Ife experience. WAJM 2004, 23(Suppl 1):27-31.

20. Akinwusi PO, Komolafe AO, Olayemi OO, Adeomi AA: Patter of sudden death at Ladoke Akintola University of Teachnology Teaching Hospital, Osogbo, Southwest Nigeria. Vasc Health Risk Manag 2013, 9:333-339.

21. Akhiwu WO, lgbe AP: Deaths with medicolegal implications in the elderly: experience from Benin City, Nigeria. Asian J Gerontol Geriatr 2011, 6:35-37.

\section{doi:10.1186/s12963-014-0026-9}

Cite this article as: Pelemo et al: An autopsy review of sudden unexpected natural deaths in a suburban Nigerian population. Population Health Metrics 2014 12:26. 